\title{
Experienced Practitioners' Beliefs Utilized to Create a Successful Massage Therapist Conceptual Model: a Qualitative Investigation
}

\author{
Ann Blair Kennedy, LMT, BCTMB, DrPH, ${ }^{1 *}$ Niki Munk, LMT, ${ }^{2} D^{2}$ \\ ${ }^{1}$ Department of Biomedical Sciences, Division of Behavioral, Social, and Population Health, University of South Carolina \\ School of Medicine Greenville, Greenville, SC, ${ }^{2}$ Department of Health Sciences, School of Health and Rehabilitation \\ Sciences, Indiana University, Indianapolis, IN, USA
}

Background: The massage therapy profession in the United States has grown exponentially, with $35 \%$ of the profession's practitioners in practice for three years or less. Investigating personal and social factors with regard to the massage therapy profession could help to identify constructs needed to be successful in the field.

Purpose: This data-gathering exercise explores massage therapists' perceptions on what makes a successful massage therapist that will provide guidance for future research. Success is defined as supporting oneself and practice solely through massage therapy and related, revenue-generating field activity.

Participants and Setting: Ten successful massage therapy practitioners from around the United States who have a minimum of five years of experience.

Research Design: Semistructured qualitative interviews were used in an analytic induction framework; index cards with preidentified concepts printed on them were utilized to enhance conversation. An iterative process of interview coding and analysis was used to determine themes and subthemes.

Results: Based on the participants input, the categories in which therapists needed to be successful were organized into four main themes: effectively establish therapeutic relationships, develop massage therapy business acumen, seek valuable learning environments and opportunities, and cultivate strong social ties and networks. The four themes operate within specific contexts (e.g., regulation and licensing requirements in the therapists' state), which may also influence the success of the massage therapist.

Conclusions: The model needs to be tested to explore which constructs explain variability in success and attrition rate. Limitations and future research implications are discussed.

KEY WORDS: massage therapy profession; Super's theory; career development; career longevity; analytic induction

\section{INTRODUCTION: BACKGROUND \& PURPOSE}

The massage therapy profession has grown exponentially in the United States (US) over the past 25 years and $35 \%$ of massage therapists have been in practice for three years or less. ${ }^{(1)}$ This dearth of field-wide cumulative experience can be explained by a combination of several contextual factors, and harbors negative implications for massage therapy. Industry reports indicate that massage therapists (MT) in the US are more than $80 \%$ female, have a median age in the 40s, and most have some college education. ${ }^{(1,2)}$ Massage therapy is often pursued as a second career ${ }^{(1,2)}$ and, unfortunately, many new to the field are not staying long in their new massage therapy careers. Less than half (43\%) of US massage therapists have been in practice for more than seven years. Economic information about the profession may provide clues to these career longevity-related statistics, but at times appear to be inconsistent. The Bureau of Labor and Statistics reports the current average income for massage therapists is $\$ 38,040,{ }^{(3)}$ while the American Massage Therapy Association (AMTA) reports average income much lower at $\$ 24,519^{(4)}$ and Associated Bodywork and Massage Professionals' 2011 data indicates the average income for independent massage therapists is $\$ 25,365$ versus massage therapy employee's average income being $\$ 19,605$. $^{(1)}$ The lower income data from the professional associations also point to another statistic from the AMTA showing only $55 \%$ of massage therapists earn income solely from massage therapy. ${ }^{(4)}$

While these descriptive data indicate that massage therapy may not be an enduring career, the many "why"s for this phenomena (i.e., Why do massage therapists leave the profession? Why do those who stay in the profession, stay? Why is it that some therapists manage to make massage therapy a lasting career? ) can only be speculated, because specific investigation to address these inquiries have yet to occur. Descriptive information provided by industry reports and anecdotal field evidence is interesting, but critical inquiry along with formal research is needed to understand longevity trends and contributing factors. One 
of several potential starting places for such a line of inquiry is practitioners who have been in the massage therapy field for an extended period of time and who have been successful in supporting themselves and their practices with massage therapy as their only form of employment. For the remainder of this paper, we define supporting oneself and practice solely through massage therapy and related revenue-generating field activity as "being successful". It should be noted that this definition does not take into account professional satisfaction or positive clinical outcomes; however, with the relatively low average income levels noted for the profession, supporting oneself through massage therapy can be a beginning step to conceptualizing a successful massage therapist.

This paper describes a 2014 data-gathering exercise conducted with 10 successful massage therapy professionals, to identify the qualities needed for enduring and successful massage therapy careers.

\section{METHODS}

Social media discussions held on multiple massage therapy professional groups on Facebook between approximately 2012-2014 sparked the interest for the exercise. ${ }^{(5-7)}$ The exercise-inspiring discussions considered what it takes to make a "good" massage therapist, with multiple concepts and theories deliberated including, but not limited to, the ability to make a connection with clients, having "the hands", and having an in-depth knowledge of anatomy and physiology. While good and successful (as defined here) are not synonymous with regard to massage therapists, it does stand to reason that a therapist who is not "good" would be success-challenged. Additionally, a good massage therapist may be one who can connect with clients and achieve positive clinical outcomes; however, if they are unable to attract clients, success may appear elusive as they may not be able to support themselves. For the purposes of this data-gathering exercise, it was assumed that contributing concepts for "good" therapists also apply to a therapist's success potential.

Super's theory indicates that careers develop throughout an individual's lifespan and are influenced by both personal and external/social factors. ${ }^{(8-11)}$ Super's career development theory was used as a framework to organize the many relevant postulations highlighted in the social media discussions sparking this enquiry. Figure 1 presents identified concepts from the social media discussions within Super's framework for the career development theory to serve as an initial conceptual model for defining qualities/components of a successful massage therapist for the data-gathering exercise. Identified personal factors include talent, communication skills, and stamina; external factors include initial education, continuing education, and membership in a professional organization.

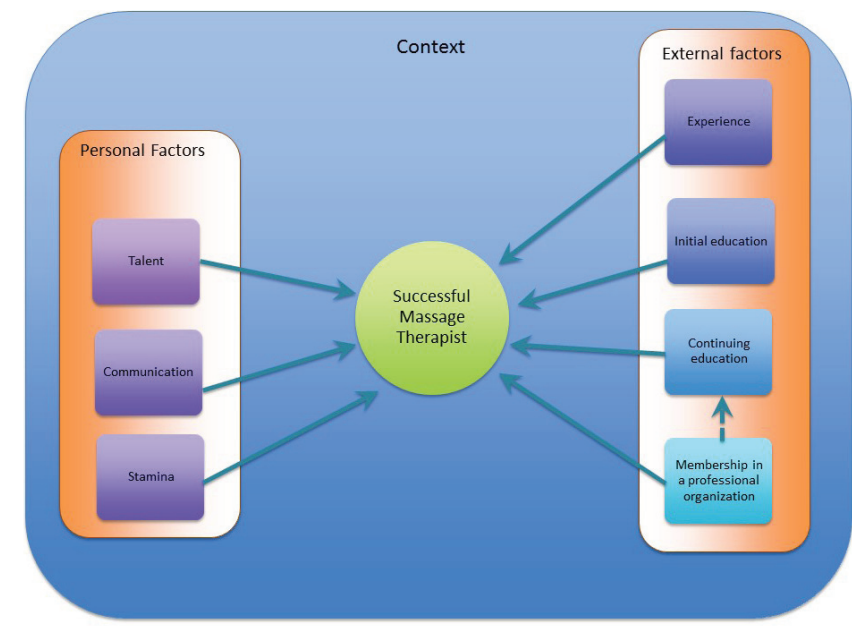

FIGURE 1. Analytic induction framework conceptual model of a successful massage therapist created from literature and social media discussions used to help formulate the interview guide.

\section{Data Gathering Exercise}

Methodology for the exercise was informed by an analytic induction which begins with a hypothesis or phenomenon to be explained, rather than generating a hypothesis or discovering a phenomenon as is seen in other qualitative methodologies. ${ }^{(12-16)}$ The hypothesis or phenomenon is used as a lens through which to examine particular concepts or instances for alignment with the hypothesis/phenomenon. If the concepts/instances do not align with the hypothesis, then the hypothesis is revised or the concept/instance is removed from analysis. ${ }^{(12,13,14,17-18)}$ For this exercise, the hypothesis was the initial conceptual model supported by Super's framework for a successful massage therapist (Figure 1), which was guided by literature and social media discussions. This framework/ hypothesis informed related aspects of the developed interview guide (Table 1) which was reviewed by a research expert. The University of South Carolina Institutional Review Board evaluated and granted approval (Pro00035845) for the activities described in this paper. All activities related to this exercise was performed by, first author (ABK), a licensed massage therapist since 1999, Board Certified in Therapeutic Massage and Bodywork, active volunteer for two massage therapy organizations (i.e., AMTA, MTF), and who at the time was a doctoral candidate in the Health Promotion, Education, and Behavior department at the University of South Carolina.

\section{Sampling}

Convenience sampling was used to find at least nine participants meeting the inclusion criteria for the exercise: practicing massage therapist with five or more years of experience. It was determined that five years provides enough time to settle into massage 
TABLE 1. Interview Guide

\begin{tabular}{|c|c|}
\hline Number & Question \\
\hline 1. & How many years have you been a massage therapist? \\
\hline 2. & $\begin{array}{l}\text { What state do you currently practice massage therapy? } \\
\text { Have you practiced in other states? (If yes) Which } \\
\text { ones? }\end{array}$ \\
\hline 3. & How many hours was your initial massage education? \\
\hline 4. & $\begin{array}{l}\text { What is your current role or roles in the massage } \\
\text { therapy profession? }\end{array}$ \\
\hline 5. & Which professional organization(s) do you belong to? \\
\hline 6. & What do you think makes a good massage therapist? \\
\hline 7. & $\begin{array}{l}\text { To what extent do you think setting or environment } \\
\text { plays a role? How? }\end{array}$ \\
\hline 8. & $\begin{array}{l}\text { Here is a list of possible categories for being a good } \\
\text { massage therapist. Could you place them in order of } \\
\text { importance as to what makes a good massage therapist } \\
\text { in your mind? (Hand cards to participant; write on } \\
\text { blank cards any categories indicated from question 6). } \\
\text { Cards labeled: } \\
\text { - Initial education } \\
\text { - Continuing education } \\
\text { - Being part of a professional organization } \\
\text { - Communication } \\
\text { - Stamina } \\
\text { - Talent }\end{array}$ \\
\hline 9. & $\begin{array}{l}\text { What if anything do you fell is missing from the list? } \\
\text { (add to blank cards if not previously done) }\end{array}$ \\
\hline 10. & $\begin{array}{l}\text { I'd like you to tell me what each one means to you with } \\
\text { the idea of how it contributes to being a good massage } \\
\text { therapist. Let's start with the one you chose as most } \\
\text { important. }\end{array}$ \\
\hline 11. & Thank you, do you have any final thoughts? \\
\hline
\end{tabular}

therapy practice and, if providing 20 hours $^{(19)}$ of hands on work a week, allows for potentially more than 5,000 hours of clinical treatments. Prior to three different industry meetings (i.e., a Massage Therapy Foundation Board of Trusties Meeting, 2014 AMTA National Convention, AMTA Chapter Volunteer Orientation Program), a notice was placed on social media to ask if meeting attendees would be willing to participate in the project. All those responding to the enquiry with participation interest were interviewed with one exception due to scheduling conflicts. An additional therapist was directly invited to participate because of a prior indicated interest during a related conversation. All participants provided informed consent and no incentives were offered for participation.

\section{Design, Procedures, and Data Collection}

Techniques from qualitative research methodologies were used to guide the exercise. Semistructured qualitative interviews were conducted using an analytic induction framework; $(12,14,16)$ index cards with concepts printed on them were utilized to enhance conversation and explore underlying understanding of the concepts. ${ }^{(12,13,14,17-18)}$ This method is similar to other studies using the index card process. ${ }^{(20,21)}$ All interviews were in-person and conducted in private to semiprivate (e.g., corner of a meeting room or coffee shop) locations chosen by the interviewee and interviewer together. Interviews ranged in length from 10 to 27 minutes and all were audio-recorded.

After initial demographics were obtained, interviewees were asked what they thought makes a good massage therapist and to what extent they feel environment has a role. Participants were given eight index cards, two of which were blank and six labeled with the Super's framework internal and external factors (talent, communication, stamina, initial education, continuing education, professional organization membership). The blank cards were for participants to add factors they felt were missing from the initial conceptual model for successful massage therapists. The interviewees were asked to organize the cards in order of importance for what makes a good massage therapist. After participants completed their card organization, they were asked to describe the "picture" their organized cards made and were asked to discuss each factor in detail. Interviews concluded with thanks and invitation for participants to offer any additional thoughts. Field notes were taken throughout each interview and interviewee arranged card layouts were photographed for future reference.

\section{Data Analysis}

Each interview was transcribed and an iterative process of interview coding and analysis guided by an analytic induction framework ${ }^{(12,13)}$ was utilized to investigate arising themes participants associated with a successful massage therapist. QRS NVivo 10 was used for qualitative data management. ${ }^{(22)}$ Based on analysis, the initial "what makes a successful massage therapist conceptual model" developed for the study (Figure 1) was revised. The concluding data analysis step involved sending the revised conceptual model and results to all participants for their final input in a process called member-checking. ${ }^{(23)}$ Member-checking was conducted as direct electronic communications (multiple if needed), and allowed for participants to ensure clear representation of their thoughts and quotes.

\section{RESULTS}

Table 2 details the characteristics of the 10 participants. While disproportionally fewer men participated, the gender representation is reflective of the massage therapy profession which is $83 \%-88 \%$ female. ${ }^{(1,2)}$ Most participants had over 15 years of massage therapy practice experience and many had practiced in more than one state, held multiple memberships in professional groups, and served in a variety of roles for the profession. All participants had 
Table 2. Participants Characteristics $(\mathrm{N}=10)$

Variable

Gender

Number of hours of initial education

Years in Practice

States where participants have practiced (n, not exclusive)

Association/Group membership

(n, not exclusive)

Roles in the massage therapy profession ( $\mathrm{n}$, not exclusive)
Frequency
Female $=8$ Male $=2$

Median: 677.5

Range: 500 to 1200

Median: 17.5

Range: 8 to 43

CA (2), CT (3), DC (1), MA (2), ME (1), MI (1), NJ (1), NY (1), OK (1), PA (1), RI (1), SC

(1), WA (1)

American Massage Therapy Association (8), American Bodywork and Massage Professionals (2), Society for Oncology Massage (2), American College of Sports Medicine (1), Board Certified in Massage Therapy (2), National Association of Holistic Aromatherapists (1), Women in Business Groups (2), NY State Society of Medical Massage therapists (1), Doula International (1), Alliance for Teachers of MT Education (1), Athletic Trainers Association (1), Kinesio Taping Association (1), Fascia Research Society (1), and Local Chamber of Commerce (1)

Practitioners (10), Initial Education Providers (5), Continuing Education Providers (4), Volunteers both in the community and in the profession (10) some previous connection with the first author, including volunteering for the same professional organizations and being "friends" on social media. Because of these previous relationships, an additional researcher was added to help determine the trustworthiness of the results and reduce potential biases.

Based on participant card organization patterns and interview and field notes data, four main themes emerged for what makes a successful massage therapist: establish effective therapeutic relationships, develop massage therapy business acumen, seek valuable learning environments and opportunities, and cultivate strong social ties and networks. The data also determined that the four themes operate within specific contexts (e.g., regulation and licensing requirements in the therapist's state) which may also influence the potential for therapist success.

\section{Theme 1: Effectively Establish Therapeutic Relationships}

Participants indicated that establishing a therapeutic relationship with clients is essential and this is done through the avenues of communication, professionalism and through personal aspects of the therapist. Not much literature has focused on the therapeutic relationship between massage therapist and clients; however, these therapeutic relationships may have impacts on health outcomes. ${ }^{(24-34)}$ The data indicated repeatedly that communication is likely a large piece of the therapeutic relationship establishment puzzle. Massage therapists must be able to communicate with clients clearly, gain their trust, and establish a connection with them.

MT10: "Communication and listening is key to being able to facilitate any good health care."
MT1: "The communication skills that I learned in school were phenomenal. To learn to couch things in a way that aren't judgy to help people to come to a place where they are in acceptance of their bodies, that things are always in flux. The skills that they gave me, to be able to use the right words for those things, I think that's why I view myself as a successful therapist. And I think that is a huge piece of it. I think lots of people can do the bodywork, but if you don't have the ability to talk and establish rapport, and help people understand and educate them. Then the communication is the key."

MT8: "I feel to be successful in any part of your life you need to have strong communication skills with the people around you. So, this one is all encompassing for me."

Establishing a therapeutic relationship relies on personal factors. According to the participants, these personal factors include the therapist needing to be adaptable, caring, mature, and healthy. Having good boundaries and ethics and presenting a professional appearance were also considered important.

MT4: "If you are healthy and you are fit and you receive regular bodywork and you do all the things that you are supposed to be doing that contributes to your stamina, but, also that sets an image for you as a professional. This person knows how to take care of themselves. So, I would probably listen to someone to help me take care of myself if they look like they take care of themselves. So yes, you need to have strength, you need to have endurance, you need to have a good diet, you need to have regular sleep, you 
need to be properly hydrated, you need to be flexible, all of that. You need to have the proper footwear and clothing and all that stuff."

MT10: "Being caring and ethical is part of who we are and it makes us professionals."

\section{Theme 2: Develop Massage Therapy Business Acumen}

Participants identified the business of massage therapy as also important for therapist success, no matter if therapists were self-employed or employees. The participants noted the necessity of understanding business on all levels and the necessity of massage therapists to make business decisions, hence the term acumen as defined as "keenness and depth of perception, discernment, or discrimination especially in practical matters". ${ }^{(35)}$ To develop massage therapy business acumen, therapists must have some level of stamina to be able to perform the work, as well as the stamina to stay in the business, some business sense, good communication skills outside of communicating with clients, and a talent for massage therapy. Stamina was seen not just as physical stamina, but also emotional stamina and the ability to do what needs to be done throughout the day businesswise.

MT9: "Stamina means I can do multiple sessions without it being negatively damaging. It can also be emotional, and physical stamina can be built. The clinical experience will also help create stamina. Stamina will also help you to stay in the profession."

Business sense was discussed as not just strictly relating to the business concepts of marketing and management, but also of therapists needing clinical experience, a need for entrepreneurial skills, and the need for specialization in the massage therapy field. The participants indicated that clinical and specialized massage therapy skills and business abilities worked hand in hand to help massage therapists gain more success and be fulfilled professionally.

MT5: "You need to find a niche nowadays to come into the profession. Extra skill is needed. It has gotten too easy to go to massage school. Massage is hard, owning a business is hard, you aren't going to get rich in this business and people think they will as soon as they get out of school."

MT6: "You can be a good massage therapist but not a successful massage therapist. You can be a very, very talented person at the table in doing bodywork but that doesn't mean you will have a successful business. And I think that is where the main disconnect comes in because many people are very good but they can't tap into other people's skills. They are kind of floating around out there floundering because they can't get the bodies on the table or they can't do their taxes or whatever it is that they have missing skills. And then others that choose to work for a place where all they are doing is massage, then ALL they are doing is massage and too close together and for too long. Because they are also making less money, because they are working for someone who is doing all those other things that they can't do. I think it is the big picture of having a practice that makes for having a fulfilling profession, a fulfilling career. Because then you get to have your table time, and you also get to do the business building and caretaking because you can't just be at the table 10 hours a day."

Communication was not just discussed in the sense of establishing effective therapeutic relationships; communication was also essential for developing business acumen and being able to communicate to other professionals and other health care providers.

MT5: "Communication will help with marketing, and working with clients both on and off the table. Communication is crucial for everything."

MT4: "Communication is the business piece: you have to be able to communicate across professions, with other MTs, with your community, and with your client"

Having massage therapy talent, sometimes referred to as "having good hands", appears to be the unique quality of understanding how to touch appropriately and with the correct amount of pressure for the tissue and/or problem area. Talent was not deemed as important as other factors in relation to business acumen. While the data indicated talent as a piece of the puzzle, therapists can still be successful if they are lacking in talent if they are stronger in other important areas.

MT2: "I tell my students that talent is only part of it. If you can communicate well with someone and can act professionally with that person, you can actually give a mediocre massage and still be successful. On the other hand, someone who gives a stellar massage but has no tableside manner will not succeed. The clients are never going to come back. I hear therapists say 'I am a really good therapist, everyone tells me I am good'." Well that's great, but can you communicate with people and do the professional things you need to do in order to get them to come back?"

MT5: "Talent is far down on the list, if you don't have a skill set from education, no matter if you have talent or not, you will not succeed." 


\section{Theme 3: Seek Valuable Learning Environments and Opportunities}

Participants stressed the importance of learning, both with continuing and initial education. Some participants felt that continuing education was the path to success, while others felt that if an initial education foundation was not established, a massage therapist could never be successful. Continuing education is seen as essential to help build a massage therapist's field expertise and clinical skills while facilitating engagement with the profession as in other health care professions. ${ }^{(36)}$ Such lifelong learning is essential for professional development and may help improve practice. ${ }^{(36)}$ Continuing education was also seen as connected to being part of a professional organization; education offerings through a professional association are possibly considered more credible.

MT6: "You need learn new skills with continuing ed."

MT3: "I put continuing ed before initial education because this [initial education] tells you how to pass your state boards, it doesn't tell you how to be a massage therapist or any of those real important pieces. This [initial education] is the foot in the door, and this [continuing ed] is rest of the way to the skill set to the life career."

Some participants felt that initial education is of the utmost importance, while others considered it just a stepping-stone to start a massage therapist off but more steps would be needed for ultimate success. Some participants indicated that initial education is foundational for all therapists but will not help a person necessarily grow in the profession.

MT8: "Initial education is most important you must know the body and systems you must know your subject."

MT5: "Initial education is your base — and it needs to be good quality ed. If you have crappy education then you cannot be successful. Must have a good anatomy, science ed..."

\section{Theme 4: Have Strong Social Ties and Networks}

Every participant mentioned some form of external support was needed for massage therapist success. Research indicates social ties and networks can help improve health and well-being and act as stress buffers ${ }^{(37,38)}$ which may provide the mechanisms through which support from others benefits therapists seeking success in the field. Participants felt such social and supportive ties were essential and indicated being part of a professional organization, business and family support systems, and mentoring as related to this theme.

Several interviewees mentioned being part of a professional organization giving a sense of support. Massage therapists generally work in isolation ${ }^{(32,39)}$ and therapists connecting with the greater profession seems most easily done by being a part of a professional organization. Identified support sources were not limited to professional organization; supportive work environments were also noted foreshadowing the importance of context within which therapists work for success.

MT8: "It's not all technical skill that makes up a good MT. Other relationships that are built are important to stay in the field. Volunteering, going to meetings, being with others keeps you motivated. Attending conferences helps to meet new people and learn new techniques. That support system is important."

MT7: "The [business] partnership helped me to stay in practice. We each have strengths so we all contribute to the business it's not one person doing everything. It's not one person doing accounting and massage and everything that goes along with it. It's we each have an aspect that we take care of, so we share in the managerial duties and that way we can focus on massaging our clients. And we can also support each other by keeping up with continuing education and training each other."

MT4: [Being part of a professional organization] ... "gives a feeling of a professional community. It's the icing on the cake. The social piece is helpful and helps you to grow and helps with the isolation of the solo practice. It can also help the profession not just the individual. Being the member of multiple organizations can really help feed all my interests."

While not highlighted during the original interviews and initial data analysis, mentoring came up specifically during member-checking. Mentorship aligns with the Strong Social Ties and Network theme in light of Thoits' studies on social support. ${ }^{(37)}$ Briefly, Thoits determined that social support is emotional, informational, and/or instrumental ${ }^{(37)}$ which is reflective of strong mentoring relationships. ${ }^{(40-42)}$ Mentoring is also tied to social support and professional development in the literature. $(41,43,44)$

MT1: "Mentoring has saved my sanity and my practice by giving me fresh perspectives on everything from marketing to boundary violations/ethical issues to treatment plans and options. Sometimes even just having a fellow LMT [licensed massage therapist] commiserate even if they have no solutions or advice to offer 
has meant the world to me. The career path for a solo practitioner such as myself is very isolating, lonely at times even."

\section{Context}

The context and/or environment in which the therapist works was clearly identified as having great influence on each of the factors categorized to their various theme. Licensure and a supportive work environment were specifically spoken about as to having influence on a therapist's likelihood to be successful.

MT10: "Setting plays a role in their success. It helps if they have a support system and if they work with others. Licensure has just come to Michigan and will probably weed out those who haven't had the education."

MT2: "If you are in a setting where you feel you aren't supported or treated fairly then that will make a huge difference, then if you work somewhere where your opinion matters that really changes the environment. [The environment plays a] HUGE role [in therapist's success]."

\section{Revised Conceptual Model for Massage Therapist Success}

The data-gathering exercise's themes and subthemes lent themselves to the revision of the successful massage therapist conceptual model (Figure 2). How well massage therapists master each model construct may influence how successful they become in their career.

\section{DISCUSSION}

The participant interviews led to a revision of the initially proposed conceptual model for a successful massage therapist. The revised model was based upon the themes and subthemes determined from the interviews including effectively establish therapeutic relationships, develop massage therapy business acumen, seek valuable learning environments and opportunities, and have strong social ties and networks. Interestingly, neither the initial model nor the interviews with participants brought forward the concept that a successful massage therapist would have consistently positive client outcomes. This could simply be an assumption by therapists that a good massage therapist would provide positive outcomes; however, it should be noted that client outcomes were not mentioned nor a part of either conceptual model.

The therapeutic relationship has been investigated in the medical community ${ }^{(24,25)}$ and, to a limited extent, in Complementary and Integrative Medical models. ${ }^{26,31,45)}$ However, therapeutic relationships

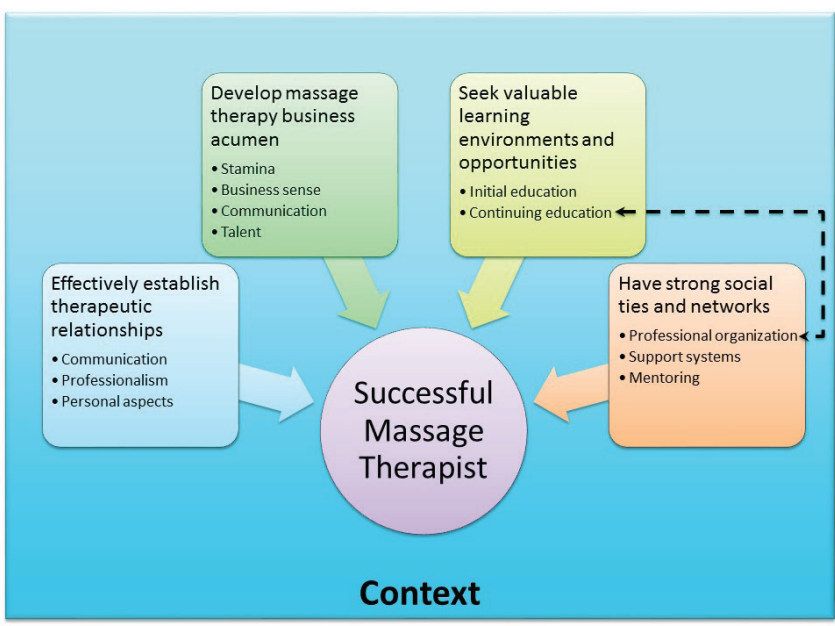

FIGURE 2. Final conceptual model of a successful massage therapist developed from interviews and analysis guided by analytic induction framework yielded four constructs including: effectively establish therapeutic relationships, develop massage business acumen, seek valuable learning environments and opportunities, have strong social ties and networks.

have not been robustly explored in the massage therapy profession; ${ }^{(24-27,31-34,45,46)}$ and an established therapeutic relationship seems vitally important when such intimate contact as therapy takes place. New research has established therapeutic relationship as an integral part of massage therapy and even goes so far to state that massage actually becomes massage therapy within the context of the therapeutic relationship. ${ }^{(32)}$ These developing concepts indicate future research on therapeutic relationships' impact on patient outcomes are needed ${ }^{(32)}$ and future research should also seek to elucidate the most effective ways to establish therapeutic relationships within massage therapy encounters, as well as how this relationship may influence health outcomes. The literature highlights how good communication can improve therapeutic relationships, ${ }^{(25,27,47)}$ a concept reflected in the revised successful massage therapist model. Establishing education programs that help therapists understand how to effectively communicate with patients may help to improve their future success within the massage therapy profession. Finally, professionalism and personal aspects can influence the therapeutic relationship according to our proposed revised model. Professionalism includes understanding and establishing proper and ethical boundaries with patients. The literature indicates that strong boundaries can help improve therapeutic relationships within non-massage therapy health care professions ${ }^{(48-50)}$ and it is well reasoned to expect such professionalism to also positively impact the therapeutic massage relationship ${ }^{(51-53)}$ — indicating professionalism and developed therapeutic relationships may be reciprocal in nature.

Massage therapists' success also seems to be tied to their ability to develop massage therapy business 
acumen which includes stamina, business sense, and communication. Menard has pointed out areas for potential competencies within the massage therapy profession $^{(54)}$ and while some pieces of massage therapy business acumen are mentioned (i.e., communication skills and electronic medical records), there is no mention of business education. Business skills is an area that seems to be lacking in massage therapy education per study participants' perceptions based on their prior and current involvement in foundation and/or continuing massage therapy education. Formal type business classes, as well as continuing education specific to and taught by business professionals/ educators, may be helpful to increase the success of massage therapists. Physical and mental stamina has been noted as essential for success in other health care careers such as psychologists, ${ }^{(55)}$ and Adams et al. ${ }^{(56)}$ noted that stamina is considered part of resilience for medical professionals required to maintain and provide high-quality health care. Logic dictates the importance of physical stamina for a career as physically demanding as massage therapy yet no research points to the need for a massage therapist's mental stamina, although participants indicate such stamina as vital for success. A lack of emotional stamina could lead to emotional exhaustion which is a component of burnout seen in other health care professions (57-59) though not considered in the massage therapy literature, to date. Investigating burnout in massage therapists could shed light on the attrition in the field. Finally, the scientific literature appears to mirror participant suppositions about talent, meaning some find talent to be important for success and others do not. Tsay ${ }^{(60)}$ found that individuals with varying levels of entrepreneurship tended to prefer those who were naturally talented versus those who strived for success; however, in the practical health care world, some fields find that great hand-skill did not correlate with success, indicating that innate talent may not be a dominate necessity for success in practitioner provided care. ${ }^{(61)}$

Our revised conceptual model for a successful massage therapist identified seeking valuable learning environments and opportunities as a key component, with initial and continuing education mediums as subcomponents. A lack of massage therapy education and credentialing standardization across the United States challenges this important model component in that no clear competencies for entry or advanced level MTs have been identified around which educational opportunities can develop. ${ }^{(54)}$ However, professional development is vital for assisting professionals to grow in their practice and improve clinical competency; $(36,62)$ and continuous learning, whether through initial or continuing education, is essential for massage therapists. Massage therapists may be motivated to seeking out these learning opportunities to gain mastery of their craft and improve their clinical skills. Aspiring and experienced MTs have multiple opportunities to consider for both initial and continuing education. Initial education is important and foundational; however, the inconsistency of massage therapy education in the US has been pointed out. ${ }^{(54)}$ Continuing education helps stoke the passion for the profession while seeking to increase skills and move therapists toward success of a career in massage therapy. The variety of continuing education available runs from simple online courses ${ }^{(63)}$ to multi-week in-person hands-on accredited curriculums. ${ }^{(64)}$ Continuing education topics range from evidence based coursework to classes that are more metaphysical/new-age/paranormal in nature $^{(65)}$ (or as some refer to them: "woo-woo"(66)), with varying degrees of scientific foundation; those less founded on evidence risk consideration as (in the authors' opinions) anecdotal ethereal hyperbole. Education, both initial and continuing, is tied to a massage therapists' success, though the quality and extent of that educations' impact on success should be investigated.

We were surprised by the extent to which study participants determined social ties and networks as important components of success. While networking may be necessary for maintaining a successful practice to bring in clientele, the participants did not indicate the social ties and networks for client generation, but more for business and emotional support. Mann et al. ${ }^{(67)}$ indicated that discussing cases with other health professionals can help with future problem solving, and supportive networks and social media outlets may provide massage therapists with a medium through which to process or troubleshoot practice challenges. Social support has been tied to multiple positive health outcomes (e.g., stress buffering, improved selfesteem, longevity) in various populations, ${ }^{(37,68-70)}$ and seems likely an essential element for those in isolating professions such as massage therapy. Other health care professions have noted the positive effects of mentoring to help improve the success of students and young professionals, support leadership capabilities, and reduce mentee stress, ${ }^{(41,43,71)}$ and often implement formal mentorship programs aligned with education institutions. While social media may serve as informal routes through which mentor/mentee relationships can build, the massage therapy profession may be well served by replicating and implementing formal educational-aligned mentorship programs from other fields to support the success of individual therapists and the field overall. Membership and involvement with professional organizations may serve to provide mentorship and other opportunities supportive of therapist success, and also provides a link to likeminded and focused professionals and continuing education. Others have mentioned the positive impacts of being part of a professional organization and the resources those organizations can provide. ${ }^{(42)}$ Therefore, those with strong social ties and networks may have a large impact on a massage therapist's success; however, more research needs to be conducted. 


\section{Limitations}

As with all projects, the data-gathering exercise described here has its limitations including that all participants were members of at least one professional massage therapy organization which may have influenced the perceived importance of being an organization member. Additionally, the original conceptual model did not include the concept of positive patient outcomes or technical skills as a sign of success and therefore was not included within the interview guide; this flaw may leave out important concepts that may be part of success for massage therapists. The interviews themselves were short due to time constraints of the meetings being attended. The interview guide itself missed several key points including asking the massage therapists about their thoughts on the quality of touch, different modalities, and required technical skills. Transferability is limited as this was a small nonrandom sample and, while several areas of the country are represented, a majority of participants practice in the Northeast. Finally, potential researcher bias also exists as only one researcher coded and analyzed the data. To lessen this limitation, member checking was employed ${ }^{(12,23)}$ and an additional author (NM) was added to the study to review the data and results, provide expertise in writing and revision, and provide additional interpretation perspective. While limitations exist for this work's results, the intent of the data-gathering exercise was to develop a conceptual model for what makes a successful therapist which, by definition, is a work in progress and should always be considered though a cautious lens. This work is interesting, however, by virtue of the field discussion it can inspire and its potential to provide foundation for future empirical studies.

\section{Future Directions}

Future inquiries into what makes massage therapists successful should include longer and more in-depth interviews with more probing questions, as well as a more rigorous methodology. Additionally, attempting to discover if the participants themselves are successful in the field other than simply using longevity criteria as inclusion specifications should be employed. Participants could be asked if they consider themselves successful, and success could be measured by asking if they are able to make a living solely by practicing massage therapy. Those who are able to make a living at the practice of massage therapy may have those additional qualities noted in the conceptual model. Participants could be asked about percentage of repeat clientele which may help to indicate the extent to which a therapist's client base has positive outcomes; this is going on the assumption that clients who are happy with their therapy results will return for future treatments from the same therapist. Furthermore, participants could be asked about the personal rewards and professional satisfaction that are gained from practicing massage therapy, which did not occur in this case. Finally, while the fundamental framework for this exercise was based on Super's career theory, which is highly cited and is still considered relevant by some, future studies may find that the more recently developed work by Lent and Brown on Social Cognitive Career Theory may be more applicable. ${ }^{(72)}$ The revised model for what makes a successful massage therapist presented here needs to be tested to explore the extent to which constructs explain variability in success for massage therapists; further investigation into these concepts with a larger sample size and/or longer more in-depth interviews are needed.

These data are an initial first step into an investigation to discover the aspects needed for massage therapists' success. Perspectives not considered here, but that are important, include the client and those who have left the profession. Future work would do well to include these key informants in their considerations of what makes a successful therapist, and we welcome additions and alterations to our conceptual model as research progresses. Additionally, we welcome and encourage the use of our conceptual model's constructs for testing and application to the creation of professional competencies which could help drive changes in massage therapy education.

\section{ACKNOWLEDGMENTS}

Special acknowledgement is extended to the participants for taking their time to sit down and share their knowledge. Thanks also to Ruth Saunders, $\mathrm{PhD}$, for her guidance and support on this manuscript. Leslie Young, $\mathrm{PhD}$, was also instrumental in obtaining much-needed information for the background section of the paper.

\section{CONFLICT OF INTEREST NOTIFICATION}

No funding supported this project and the authors report no conflicts of interest.

\section{COPYRIGHT}

Published under the CreativeCommons AttributionNonCommercial-NoDerivs 3.0 License.

\section{REFERENCES}

1. American Bodywork and Massage Professionals. Massage profession metrics [Internet]. [Retrieved 2014 Nov 14]. Available from: http://www.massagetherapy.com/media/metrics_income_employment.php

2. American Massage Therapy Association. Massage Profession Research Report 2014 [Internet]. Evanston, IL: American 
Massage Therapy Association; 2015. Available from: https:// www.mpc.edu/home/showdocument?id=3922

3. Bureau of Labor Statistics, U.S. Department of Labor. Occupational Outlook Handbook 2016-2017, Massage Therapists [Internet]. [Retrieved 2016 Dec 30]. Available from: https:// www.bls.gov/ooh/healthcare/massage-therapists.htm

4. American Massage Therapy Association. Massage Therapy Industry Fact Sheet | American Massage Therapy Association [Internet]. 2016 [Retrieved 2016 Dec 30]. Available from: https://www.amtamassage.org/infocenter/economic_industryfact-sheet.html

5. Science of Massage Therapy, Meditation, and Related Topics [Facebook Public Group]. (2013). [Retrieved 2016 Dec 30]. Available from: https://www.facebook.com/groups/343343539076668/

6. Largest Facebook Massage Therapist Network [Facebook Closed Group]. (n.d.) [Retrieved 2016 Dec 30]. Available from: https://www.facebook.com/groups/55087618623/?ref=br_rs

7. Massage Therapists [Facebook Public Group]. (2013). [Retrieved 2016 Dec 30]. Available from: https://www.facebook. com/groups/611431842200765/

8. Super DE, Hall DT. Career development: exploration and planning. Annu Rev Psychol. 1978;29:333-372.

9. Super DE. A life-span, life-space approach to career development. J Vocat Behav. 1980;16(3):282-298.

10. Gies V. Developing a personal career counseling theory: an overview of the theories of Donald Super and David Tiedman. Guid Couns. 1990;6(1):54-62.

11. Sterner WR. Integrating existentialism and super's life-span, life-space approach. Career Dev Q. 2012;60(2):152-162.

12. Patton MQ. Qualitative Research and Evaluation Methods, 3rd ed. Thousand Oaks, CA: Sage Publications; 2002.

13. Glaser BG, Strauss AL. The Discovery of Grounded Theory: Strategies for Qualitative Research [Internet]. Chicago, IL: Aldine Pub.; 1973. [Retrieved 2015 Feb 26]. Available from: http://search.ebscohost.com/login.aspx?direct=true\&scope=si te $\& d b=$ nlebk\& $d b=$ nlabk\&AN $=580315$

14. Fairweather J, Rinne T. Clarifying a basis for qualitative generalization using approaches that identify shared culture. Qual Res. 2012;12(4):473-485.

15. Robinson WS. The logical structure of analytic induction. $A m$ Sociol Rev. 1951;16(6):812-818.

16. Morse JM, Mitcham C. Exploring qualitatively-derived concepts: inductive-deductive pitfalls. Int J Qual Methods. 2002;1(4):28-35.

17. Parry C, Chesler MA. Thematic evidence of psychosocial thriving in childhood cancer survivors. Qual Health Res. 2005;15(8):1055-1073.

18. Bloor M, Sampson H, Baker S, Dahlgren K. Useful but no Oracle: reflections on the use of a Delphi Group in a multimethods policy research study. Qual Res. 2015;15(1):57-70.

19. American Massage Therapy Association. Massage Profession Research Report 2015 [Internet]. Evanston, IL: American Massage Therapy Association; 2016. =

20. Heslin KC, Hamilton AB, Singzon TK, Smith JL, Anderson NLR. Alternative families in recovery: fictive kin relationships among residents of sober living homes. Qual Health Res. 2011;21(4):477-488.

21. Olson K, Zimka O, Stein E. The nature of fatigue in Chronic Fatigue Syndrome. Qual Health Res [Internet]. 2015;25(10).
[Retrieved 2015 Jun 17]. Available from: http://qhr.sagepub. com/cgi/doi/10.1177/1049732315573954

22. QSR International Pty Ltd. NVivo qualitative data analysis software [Home Page] [Internet]. Melbourne, Australia: QSR International Pty Ltd.; 2012. Available from: https://www. qsrinternational.com/default.aspx

23. Carlson J. Avoiding traps in member checking. Qual Rep. 2010;15(5):1102-1113.

24. Cape J. Patient-rated therapeutic relationship and outcome in general practitioner treatment of psychological problems. $\mathrm{Br}$ J Clin Psychol. 2000;39(4):383-395.

25. Di Blasi Z, Harkness E, Ernst E, Georgiou A, Kleijnen J. Influence of context effects on health outcomes: a systematic review. The Lancet. 2001;357(9258):757-762.

26. Fogarty S, Smith CA, Touyz S, Madden S, Buckett G, Hay P. Patients with anorexia nervosa receiving acupuncture or acupressure; their view of the therapeutic encounter. Complement Ther Med. 2013;21(6):675-681.

27. Maizes V, Rakel D, Niemiec C. Integrative medicine and patient-centered care. EXPLORE. 2009;5(5):277-289.

28. Prady SL, Burch J, Crouch S, MacPherson H. Controlling practitioner-patient relationships in acupuncture trials: a systematic review and meta-regression. Acupunct Med J. 2013;31(2):162-171.

29. Wall M, Wheeler S. Benefits of the placebo effect in the therapeutic relationship. Complement Ther Nurs Midwifery. 1996;2(6):160-163.

30. Werbart A, von Below C, Brun J, Gunnarsdottir H. "Spinning one's wheels": nonimproved patients view their psychotherapy. Psychother Res J. 2015;25(5):546-564.

31. Fortune LD, Hymel GM. Creating integrative work: a qualitative study of how massage therapists work with existing clients. J Bodyw Mov Ther. 2015;19(1):25-34.

32. Kennedy AB, Cambron JA, Sharpe PA, Travillian RS, Saunders RP. Clarifying definitions for the massage therapy profession: the results of the Best Practices Symposium. Int J Ther Massage Bodyw [Internet]. 2016;9(3). [Retrieved 2016 Sep 19]. Available from: http://ijtmb.org/index.php/ijtmb/article/view/312

33. LeMoon $\mathrm{K}$. Clinical reasoning in massage therapy. Int $J$ Ther Massage Bodyw. 2008;1(1):12-18.

34. Rich GJ. Massage therapy: significance and relevance to professional practice. Prof Psychol Res Pract. 2010;41(4):325-332.

35. Acumen [Def. 1]. (n.d.) Merriam-Webster Dictionary Online [Internet]. [Retrieved 2015 Jan 3]. Available from: http://www. merriam-webster.com/dictionary/acumen

36. Regehr G, Mylopoulos M. Maintaining competence in the field: learning about practice, through practice, in practice. J Contin Educ Health Prof. 2008;28(Suppl 1):S19-S23.

37. Thoits PA. Mechanisms linking social ties and support to physical and mental health. J Health Soc Behav. 2011;52(2): 145-161.

38. Thoits PA. Stress and health: major findings and policy implications. J Health Soc Behav. 2010;51(1 Suppl):S41-S53.

39. Fortune LD, Gillespie E. The influence of practice standards on massage therapists' work experience: a phenomenological pilot study. Int J Ther Massage Bodyw. 2010;3(3):5-11.

40. Pitney WA, Ehlers GG. A grounded theory study of the mentoring process involved with undergraduate athletic training students. J Athl Train. 2004;39(4):344-351. 
41. Lord JA, Mourtzanos E, McLaren K, Murray SB, Kimmel RJ, Cowley DS. A peer mentoring group for junior clinician educators: four years' experience. Acad Med J. 2012;87(3):378-383.

42. Escoffery C, Kenzig M, Hyden C. Getting the most out of professional associations. Health Promot Pract. 2015;16(3):309-312.

43. Demir S, Demir SG, Bulut H, Hisar F. Effect of mentoring program on ways of coping with stress and locus of control for nursing students. Asian Nurs Res. 2014;8(4):254-260.

44. Helgeson V, Gottlieb B. Social support. In: Cohen S, Underwood LG, Gottlieb B, editors. Social support measurement and intervention: a guide for health and social scientists. New York: Oxford University Press; 2000.

45. Mackereth PA, Booth K, Hillier VF, Caress A-L. What do people talk about during reflexology? Analysis of worries and concerns expressed during sessions for patients with multiple sclerosis. Complement Ther Clin Pract. 2009;15(2):85-90.

46. Farrelly S, Brown G, Szmukler G, Rose D, Birchwood M, Marshall M, et al. Can the therapeutic relationship predict 18 month outcomes for individuals with psychosis? Psychiatry Res. 2014;220(1-2):585-591.

47. McAllister M, Matarasso B, Dixon B, Shepperd C. Conversation starters: re-examining and reconstructing first encounters within the therapeutic relationship. J Psychiatr Ment Health Nurs. 2004;11(5):575-582.

48. Mercer SW, Reynolds WJ. Empathy and quality of care. $\mathrm{Br} J$ Gen Pract. 2002;52(Suppl):S9-S12.

49. Post SG. Physicians and patient spirituality: professional boundaries, competency, and ethics. Ann Intern Med. 2000;132(7):578-583.

50. Smith D, Fitzpatrick M. Patient-therapist boundary issues: An integrative review of theory and research. Prof Psychol Res Pract. 1995;26(5):499-506.

51. Taylor HA, McDonald EL, Moon M, Hughes MT, Carrese JA. Teaching ethics to paediatrics residents: the centrality of the therapeutic alliance. Med Educ. 2009;43(10):952-959.

52. Oerton S. Bodywork boundaries: power, politics and professionalism in therapeutic massage. Gend Work Organ. 2004;11(5):544-565.

53. National Council of State Boards of Nursing. A Nurse's Guide to Professional Boundaries. Chicago, IL: National Council of State Boards of Nursing; n.d.

54. Menard MB. Choose wisely: the quality of massage education in the United States. Int J Ther Massage Bodyw. 2014;7(3):7-24.

55. Sanders KA, Breland-Noble AM, King CA, Cubic BA. Pathways to success for psychologists in academic health centers: from early career to emeritus. J Clin Psychol Med Settings. 2010;17(4):315-325.

56. Adams $\mathrm{S}$, Camarillo $\mathrm{C}$, Lewis $\mathrm{S}, \mathrm{McNish} \mathrm{N}$. Resiliency training for medical professionals. US Army Med Dept J. 2010:48-55.

57. West CP, Dyrbye LN, Satele DV, Sloan JA, Shanafelt TD. Concurrent validity of single-item measures of emotional exhaustion and depersonalization in burnout assessment. $J$ Gen Intern Med. 2012;27(11):1445-1452.

58. Shanafelt TD, Bradley KA, Wipf JE, Back AL. Burnout and self-reported patient care in an internal medicine residency program. Ann Intern Med. 2002;136(5):358-367.

59. Arrogante Ó. [Mediator effect of resilience between burnout and health in nursing staff] [in Spanish]. Enferm Clínica. 2014;24(5):283-289.
60. Tsay C-J. Privileging naturals over strivers: the costs of the naturalness bias. Pers Soc Psychol Bull. 2016;42(1):40-53.

61. Ballard RW, Hagan JL, Cheramie T. Relationship between handskill exercises and other admissions criteria and students' performance in dental school. J Dent Educ. 2015;79(5):557-562.

62. Kawamura AA, Orsino A, Mylopoulos M. Integrating competencies: exploring complex problem solving through case formulation in developmental pediatrics. Acad Med $J$. 2014;89(11):1497-1501.

63. National Certification Board for Therapeutic Massage and Bodywork. Continuing Education Provider Search Results: Online Short Courses [Internet]. Burr Ridge, IL: NCBTMB. [Retrieved 2017 May 27]. Available from: http://www.ncbtmb. org/tools/find-approved-provider/course-results?providerid $=\&$ name $=\&$ orgname $=\&$ city $=\&$ state $=$ All $\&$ country $=$ All $\&$ title $=$ onl ine $\&$ hours $=3 \&$ category $=\&$ status $=$ Active

64. National Certification Board for Therapeutic Massage and Bodywork. Specialty Certificates [Internet]. Burr Ridge, IL: NCBTMB. [Retrieved 2017 May 27]. Available from: http:// www.ncbtmb.org/specialty-certificates/specialty-certificates

65. National Certification Board for Therapeutic Massage and Bodywork. Continuing Education Provider Search Results: Healing Crystals [Internet]. Burr Ridge, IL: NCBTMB. [Retrieved 2017 May 27]. Available from: http://www.ncbtmb. org/tools/find-approved-provider/course-results?providerid= $\&$ name $=\&$ orgname $=\&$ city $=\&$ state $=$ All \& country $=$ All \& title $=$ crystal $\% 20$ healing \&hours $=\&$ category $=\&$ status $=$ Active

66. Bertrand SW. Inroads to integrative health care: registered nurses' personal use of traditional Chinese medicine affects professional identity and nursing practice. J Evodemce-based Compliment Alternat Med [Internet]. 2010;15(1). [Retrieved 2017 May 27]; Available from: http://chp.sagepub.com/cgi/ doi/10.1177/1533210110374639

67. Mann K, Gordon J, MacLeod A. Reflection and reflective practice in health professions education: a systematic review. Adv Health Sci Educ Theory Pract. 2009;14(4):595-621.

68. Trockel MT, Barnes MD, Egget DL. Health-related variables and academic performance among first-year college students: implications for sleep and other behaviors. $J$ Am Coll Health. 2000;49(3):125-131.

69. Voltmer E, Rosta J, Aasland OG, Spahn C. Study-related health and behavior patterns of medical students: a longitudinal study. Med Teach. 2010;32(10):e422-e428.

70. Yellen SB, Cella DF. Someone to live for: social well-being, parenthood status, and decision-making in oncology. $J$ Clin Oncol. 1995;13(5):1255-1264.

71. Day M, Shickle D, Smith K, Zakariasen K, Moskol J, Oliver T. Training public health superheroes: five talents for public health leadership. J Public Health (Oxf Engl). 2014;36(4):552-561.

72. Lent RW, Brown SD. Social cognitive approach to career development: an overview. Career Dev Q. 1996;44(4):310-321.

Corresponding author: Ann Blair Kennedy, LMT, BCTMB, DrPH, University of South Carolina School of Medicine Greenville, 607 Grove Rd., Greenville, SC 29505, USA

E-mail: kenneda5@greenvillemed.sc.ed 